\title{
Awareness of Medical Workers with Early Diagnosis of Cognitive Disorders at the Primary Health Care Level in the Republic of Kazakhstan
}

\author{
Assel Tukinova $^{1 *}$, Gulnar M. Shalgumbayeva ${ }^{1}$, Zhanna A. Mussabekova ${ }^{1}$, Roza A. Abzalova ${ }^{2}$ \\ ${ }^{1}$ Department of Epidemiology and Biostatistics, Semey Medical University, Semey, Kazakhstan; "The "Demeu" Training \\ Practical Center of Family Medicine, Nur-Sultan, Kazakhstan
}

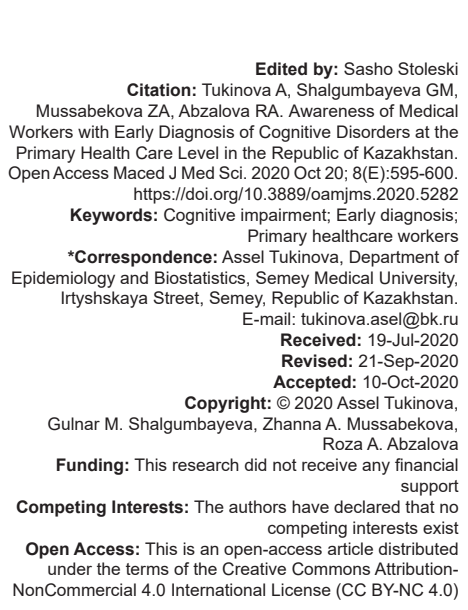

Abstract

BACKGROUND: Early detection of cognitive impairments (Cls) has been identified as one of the most important factors for the treatment of the disease. The World Alzheimer report 2011 states that the earlier a diagnosis is known, the better patients can be treated medically, patients and their family members can adapt to the development and learn to deal with the disease. Early diagnosis also leads to higher cost-effectivity, which will further improve, when treatments and social care interventions become more effective in future. It is the first-contact doctor who becomes the main figure in identifying the patient's cognitive disorders.

AIM: This study aimed to research the awareness of medical workers with early diagnosis of cognitive disorders at the PHC level in Kazakhstan.

METHODS: It was a cross-sectional study. A survey of primary healthcare workers was conducted to study the early diagnosis of $\mathrm{Cl}$ in the elderly in the period from December 2019 to March 2020. The questionnaire was developed independently according to international finding and experiences and passed the validation process. The questionnaire included questions such as age, gender, nationality, education, specialty, work experience, conduct early diagnosis of $\mathrm{Cl}$ or not, what methods respondents know, time available for admission for early diagnosis, desire to learn early diagnosis methods, and the region of residence.

RESULTS: The total number of respondents was 823 . To the question, "Do you check older patients for early cognitive impairment?" 335 (40.7\%) answered "no." To the question "Do you have time to use methods for the early diagnosis of cognitive impairment in the elderly during admission?" "no" - 354 (43\%). To the question "Would you like to learn methods for the early diagnosis of cognitive impairment in the elderly?" The answer was "yes" $759(92.2 \%)$ of respondents. This study reveals that the presence of time during admission, the region of residence, and the desire to study affect whether elder people check for early $\mathrm{Cl}$ or not, in turn, specialty, education, gender, nationality, age and work experience do not affect. We have identified a relationship of age, region of residence with the availability of time during admission to use methods for early diagnosis of $\mathrm{Cl}$, while it was absent with work experience. The region of residence, the availability of time during admission, and education influenced the respondents' desire to learn early diagnosis methods, while age and work experience did not.

CONCLUSION: The problem of early diagnosis of $\mathrm{Cl}$ in the elderly at the $\mathrm{PHC}$ level is relevant and not fully understood. Early detection of $\mathrm{Cl}$ at the $\mathrm{PHC}$ level is a key element in the fight against such a serious condition as dementia.

\section{Introduction}

Cognitive impairments $(\mathrm{Cls})$ are a major medical and social problem both in our country and around the world, which is due to their high prevalence in the population due to the aging of the population [1].

Cognitive functions - higher brain functions are: memory, attention, psychomotor coordination, speech, gnosis, praxis, counting, thinking, orientation, planning, and control of higher mental activity [2].

The world's population is rapidly aging. Between 2015 and 2050, the proportion of older people in the world is estimated to almost double, from about $12-22 \%$. In absolute terms, this is an expected increase from 900 million to 2 billion people over the age of 60 . Older people face special physical and mental health problems that need to be taken into account [3]. Old age is the most powerful and independent risk factor for developing disorders of higher brain (cognitive) functions. With the increasing number of elderly people, the number of patients with cognitive disorders increases. Therefore, it is extremely important to timely diagnose and start treatment of cognitive disorders in the elderly as early as possible, since these disorders often reach the degree of dementia when they are diagnosed late [4].

Early detection of Cls has been identified as one of the most important factors for the treatment of the disease [5]. The World Alzheimer report 2011 states that the earlier a diagnosis is known, the better 
patients can be treated medically, patients and their family members can adapt to the development and learn to deal with the disease [6]. Early diagnosis also leads to higher cost-effectivity, which will further improve, when treatments and social care interventions become more effective in future [7]. It is the first-contact doctor who becomes the main figure in identifying the patient's cognitive disorders. Early diagnosis of cognitive disorders suggests that the first-contact doctor is wary of this type of neurological disorder, especially when working with patients with risk factors for higher brain function disorders [8]. At the PHC stage, a neuropsychological study at the first contact doctor's level may be limited by simple screening scales, such as the Mini-Mental State Examination (MMSE), Montreal Cognitive Scale, and clock drawing test [9], [10].

It is predicted that the incidence of dementia in the whole world will increase almost twice every 20 years, reaching 65.7 million people in 2030 and 115.4 million in 2050. In Russia, the number of patients with dementia at the moment is already more than 1.5 million people [11]

Changes in the current demographic situation of the Republic of Kazakhstan are primarily associated with the expressed processes of aging of the population. At present, the proportion of people 65 years and older in the country has exceeded $7 \%$, thus determining its entry into the group of "aging" countries of the world. The proportion of the population of 60 years and older reached $11.2 \%$ by the beginning of 2015 , with a predicted trend of further increase by the middle of the century to $25 \%$, while the proportion of people 80 years and older will increase by more than 3 times. In the next decade, the average life expectancy of the population is projected to increase from 70.3 to 72.0 years [12], [13].

In more than half of older people, mild $\mathrm{Cl}$ progresses to dementia within 5 years. Consequently, punctual screening for $\mathrm{Cl}$ may help in early detection and timely treatment [14].

\section{Materials and Methods}

\section{Study design and procedures}

It was a cross-sectional study. A survey of PHC workers was conducted to study the early diagnosis of $\mathrm{Cl}$ in the elderly in the period from December 2019 to March 2020 in Kazakhstan.

Overall, this study comprised 823 medical workers and was permanent residents of Kazakhstan Republic. The study group consisted of Northern Kazakhstan - 95 (11.5\%), Southern Kazakhstan 200 (24.3\%), Western Kazakhstan - 87 (10.6\%),
Eastern Kazakhstan - 152 (18.5\%), Central Kazakhstan - 80 (9.7\%), and the city of Nur-Sultan - 209 (25.4\%). We tried to include all regions of Kazakhstan. All study participants gave written consent after detailed information on the study aim and confidentiality of personal data was provided. Participants were encoded with a unique code. The correspondence between this code and personal identification information is stored in a file to which only the database keeper has access. The rest had access to a coded (secure) database. Before data collection was started, the study gained the approval of the Ethics Committee of Semey Medical University (Protocol No 2, October 18, 2019).

The questionnaire was developed independently according to international finding and experiences [15], [16], [17], [18] and passed the validation process. This study aimed to study knowledge of medical workers about tools for early detection cognitive disorders. The questionnaire included questions such as age, gender, nationality, education, specialty, work experience, conduct early diagnosis of $\mathrm{Cl}$ or not, what methods respondents know, time available for admission for early diagnosis, desire to learn early diagnosis methods, and the region of residence. Medical professionals voluntarily agreed to participate in this study. We conducted a survey point-by-point throughout Kazakhstan, dividing it by regions: North Kazakhstan, South Kazakhstan, West Kazakhstan, East Kazakhstan, Central Kazakhstan, and separately the Nur-Sultan city as the capital of Kazakhstan (Figure 1).

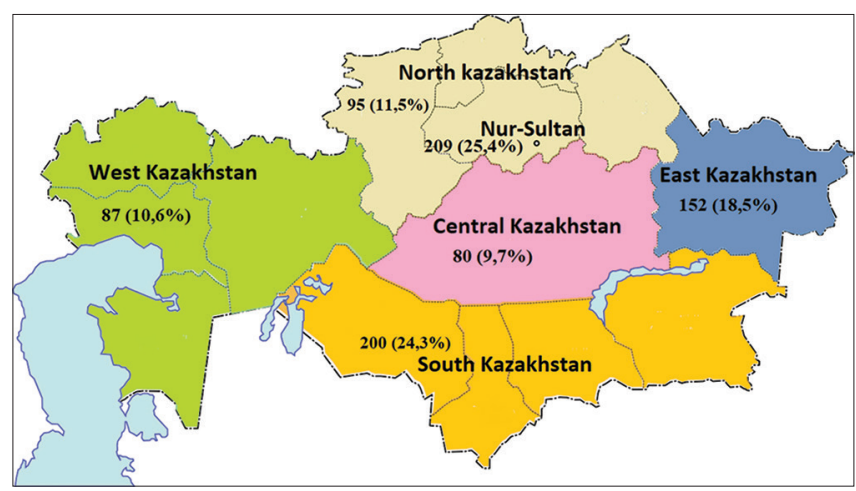

Figure 1: Distribution of the number of respondents participating in the study by region of Kazakhstan

\section{Statistical analysis}

Descriptive statistics were used to analyze the data. The choice of statistical criteria for data analysis depended on the type of analyzed variables. For qualitative data, Pearson's Chi-square was used. Statistical analysis was performed using SPSS version 20.0 (IBM Ireland Product Distribution Limited, Ireland). The level of statistical significance was set at $p<0.05$. 


\section{Results}

The total number of respondents was 823 . The minimum age was 19 years and the maximum age was 66 years. Average age was $36.45 \pm 11.6$. The number of medical workers under 25 was $151(18.3 \%)$, 26-43 years old -430 (52.2\%), 44-59 years old -224 $(27.2 \%)$, and $60-75$ years old $-18(2,2 \%)$. Among the respondents, Kazakhs were 670 (81.4\%), Russian 92 $(11.2 \%)$, and other nationalities $61(7.4 \%)$. Seventy-two $(8.7 \%)$ of the participants were male and 751 (91.3\%) female. Four hundred twelve $(50.1 \%)$ medical workers had higher education, while $411(49.9 \%)$ had secondary education. Our study involved 360 (43.7\%) general practitioners (GPs), 435 (52.9\%) nurses, and $28(3.4 \%)$ therapists. The work experience of the respondents was on average, $12.2 \pm 11$ years. Eighty-three (10.1\%) of medical workers had work experience of up to 1 year, $403(49 \%)$ from 1 year to 10 years, $141(17.1 \%)$ from 11 years under 20 years, and 196 (23.8\%) from 21 years and above.

For question about early detection of $\mathrm{Cl}$ more than half of the participants, 488 (59.3\%) answered positively, and the rest of the respondents 335 (40.7\%) answered that they have never checked patients for early diagnosis of cognitive disorders. To the question "Do you have time to use methods for the early diagnosis of cognitive impairment in the elderly during admission?" 469 (57\%) participants answered "yes", while "no" - 354 (43\%). To the question "Would you like to learn methods for the early diagnosis of cognitive impairment in the elderly?" The answer was "yes" 759 (92.2\%) of respondents, the answer "no" - 64 (7.8\%).

It should take into attention that such frequently used tool for assessing early $\mathrm{Cl}$ in many countries as MMSE, MoCA, clock drawing test, Mini-Cog, etc., among our respondents, used only 55 (6.7\%). Many of them $477(58 \%)$ did not answer to this question. Laboratory studies prescribed 9 (1.1\%) medical workers, Interview (patient and relatives) used 73 (8.9\%) people. Instrumental examinations as MRI, CT, EEG, blood pressure measurement, etc., used 51 (6.2\%) medical workers. Examination (what kind of examination was not specified by respondents) used 16 (1.9\%). Four $(0.5 \%)$ participants did not know about early diagnosis of $\mathrm{Cl}$ method in elderly people. Screening (what kind of screening was not specified by respondents) used 20 $(2.4 \%)$ respondents.

The statistical significance of the association of the variable "Do you test elderly patients for early cognitive impairment?" with other variables which calculated using Chi-square test calculated is presented in Table 1. According to data, there was a statistically significant association of the variable "Do you check elderly patients for early cognitive impairment?" with variables such as "Do you have time to use methods for the early diagnosis of cognitive impairment in the elderly during admission?"
Table 1: Relation of the variable "Do you check elderly patients for early cognitive impairment?" with other variables

\begin{tabular}{|c|c|c|c|c|c|}
\hline \multirow[t]{3}{*}{ Variable } & \multicolumn{4}{|c|}{$\begin{array}{l}\text { Do you test older patients for early } \\
\text { cognitive impairment? }\end{array}$} & \multirow[t]{3}{*}{$p, X^{2}$} \\
\hline & \multicolumn{2}{|l|}{ Yes } & \multicolumn{2}{|l|}{ No } & \\
\hline & Abs. & $\%$ & Abs. & $\%$ & \\
\hline \multicolumn{6}{|c|}{$\begin{array}{l}\text { Do you have time to use methods for the early diagnosis of cognitive impairment in the } \\
\text { elderly during admission? }\end{array}$} \\
\hline Yes & 359 & 73.6 & 110 & 32.8 & $\mathrm{p}<0.001(0.000)$ \\
\hline No & 129 & 26.4 & 225 & 67.2 & $x=134.435$ \\
\hline \multicolumn{6}{|l|}{ Region of your residence } \\
\hline North Kazakhstan & 64 & 13.1 & 31 & 9.3 & $p<0.001(0.000)$ \\
\hline South Kazakhstan & 147 & 30.1 & 53 & 15.8 & $X=82.465$ \\
\hline West Kazakhstan & 31 & 6.4 & 56 & 16.7 & \\
\hline East Kazakhstan & 84 & 17.2 & 68 & 20.3 & \\
\hline Central Kazakhstan & 21 & 4.3 & 59 & 17.6 & \\
\hline Nur - Sultan & 141 & 28.9 & 68 & 20.3 & \\
\hline \multicolumn{6}{|c|}{$\begin{array}{l}\text { Would you like to learn methods for the early diagnosis of cognitive impairment in the } \\
\text { elderly? }\end{array}$} \\
\hline Yes & 469 & 96.1 & 290 & 86.6 & $p<0.001(0.000)$ \\
\hline No & 19 & 3.9 & 45 & 13.4 & $X=25.205$ \\
\hline \multicolumn{6}{|l|}{ Your specialty } \\
\hline GP & 207 & 42.4 & 153 & 45.7 & 0.091 \\
\hline Nursing staff & 259 & 53.1 & 176 & 52.5 & $x=4.802$ \\
\hline therapist & 22 & 4.5 & 6 & 1.8 & \\
\hline \multicolumn{6}{|l|}{ Education } \\
\hline Higher & 245 & 50.2 & 167 & 49.9 & 0.920 \\
\hline Secondary & 243 & 49.8 & 168 & 50.1 & $X=0.010$ \\
\hline \multicolumn{6}{|l|}{ Gender } \\
\hline Male & 42 & 8.6 & 30 & 9.0 & 0.862 \\
\hline Female & 446 & 91.4 & 305 & 91.0 & $x=0.030$ \\
\hline \multicolumn{6}{|l|}{ Your nationality } \\
\hline Kazakhs & 401 & 82.2 & 269 & 80.3 & 0.790 \\
\hline Russians & 52 & 10.7 & 40 & 11.9 & $x=0.472$ \\
\hline Others & 35 & 7.2 & 26 & 7.8 & \\
\hline \multicolumn{6}{|l|}{ Your age (years old) } \\
\hline $0-25$ & 89 & 18.2 & 62 & 18.5 & 0.257 \\
\hline $26-43$ & 248 & 50.8 & 182 & 54.3 & $x=4.037$ \\
\hline $44-59$ & 143 & 29.3 & 81 & 24.2 & \\
\hline $60-75$ & 8 & 1.6 & 10 & 3.0 & \\
\hline \multicolumn{6}{|l|}{ Work experience } \\
\hline $0-0.99$ & 55 & 11.3 & 28 & 8.4 & 0.481 \\
\hline $1-10$ & 233 & 47.8 & 170 & 50.7 & $X=2.466$ \\
\hline $11-20$ & 80 & 16.4 & 60 & 17.9 & \\
\hline $21-\ldots$ & 119 & 24.4 & 77 & 23 & \\
\hline
\end{tabular}

( $p<0.001)$, "Region of your residence" $(p<0.001)$, and "Would you like to learn methods for the early diagnosis of cognitive impairment in the elderly?" ( $p<0.001)$. At the same time, no relation with such variables as "Your specialty" (0.091), “Education” (0.920), “Gender" (0.862), "Your nationality" (0.790), "Your Age" (0.257), and "Work experience" $(0.481)$.

The variable "Do you have time to use methods for early diagnosis of cognitive disorders in the elderly during admission?" with variables such as "your age," "your region of residence," and "work experience" is shown on Table 2.

Based on our data, there was a statistically significant relationship with the variables "your age" (0.018) and "your region of residence" (0.001). The variable "work experience" did not affect on the variable "Do you have time to use methods for early diagnosis of cognitive disorders in the elderly at the time of admission?" (0.588).

The statistical significance of differences between the variable "Would you like to learn methods for the early diagnosis of cognitive impairment in the elderly?" with the variables "Your age," "Region of your residence," "Do you have time to use methods for early diagnosis of cognitive impairment in elderly people at the time of admission?," "Education," and "Work experience" is shown on Table 3 . 
Table 2: Relation of the variable "Do you have time to use methods for the early diagnosis of cognitive impairment in the elderly during admission?" with other variables

\begin{tabular}{|c|c|c|c|c|c|}
\hline \multirow[t]{3}{*}{ Variable } & \multicolumn{4}{|c|}{$\begin{array}{l}\text { Do you have time to use methods for the } \\
\text { early diagnosis of cognitive impairment in } \\
\text { the elderly during admission? }\end{array}$} & \multirow[t]{3}{*}{$p, X^{2}$} \\
\hline & \multicolumn{2}{|l|}{ Yes } & \multicolumn{2}{|l|}{ No } & \\
\hline & Abs. & $\%$ & Abs. & $\%$ & \\
\hline \multicolumn{6}{|l|}{ Your age (years old) } \\
\hline $0-25$ & 97 & 20.7 & 54 & 15.3 & 0.018 \\
\hline $26-43$ & 238 & 50.7 & 192 & 54.2 & $X=10.008$ \\
\hline $44-59$ & 129 & 27.5 & 95 & 26.8 & \\
\hline $60-75$ & 5 & 1.1 & 13 & 3.7 & \\
\hline \multicolumn{6}{|c|}{ Region of your residence } \\
\hline North Kazakhstan & 57 & 12.2 & 38 & 10.7 & 0.001 \\
\hline South Kazakhstan & 139 & 29.6 & 61 & 17.2 & $X=21.669$ \\
\hline West Kazakhstan & 48 & 10.2 & 39 & 11.0 & \\
\hline East Kazakhstan & 73 & 15.6 & 79 & 22.3 & \\
\hline Central Kazakhstan & 38 & 8.1 & 42 & 11.9 & \\
\hline Nur-Sultan & 114 & 24.3 & 95 & 26.8 & \\
\hline \multicolumn{6}{|l|}{ Work experience } \\
\hline $0-0.99$ & 53 & 11.3 & 30 & 8.5 & 0.588 \\
\hline $1-10$ & 228 & 48.7 & 175 & 49.4 & $X=1.926$ \\
\hline $11-20$ & 79 & 16.9 & 61 & 17.2 & \\
\hline $21-\ldots$ & 108 & 23.1 & 88 & 24.9 & \\
\hline
\end{tabular}

A statistically significant relationship was found with the variables "Region of your residence" (0.005), "Do you have time to use methods for the early diagnosis of cognitive impairment in elderly people during admission?" $(p<0.001)$, and "Education" (0.004). There was no connection with the variables "Your age" (0.167) and "work experience" (0.428).

Table 3: Relation of the variable "Would you like to learn methods for the early diagnosis of cognitive impairment in the elderly?" with other variables

\begin{tabular}{|c|c|c|c|c|c|}
\hline \multirow[t]{3}{*}{ Variable } & \multicolumn{4}{|c|}{$\begin{array}{l}\text { Would you like to learn methods } \\
\text { for the early diagnosis of cognitive } \\
\text { impairment in the elderly? }\end{array}$} & \multirow[t]{3}{*}{$\mathrm{p}, \mathrm{X}^{2}$} \\
\hline & \multicolumn{2}{|l|}{ Yes } & \multicolumn{2}{|l|}{ No } & \\
\hline & Abs. & $\%$ & Abs & $\%$ & \\
\hline \multicolumn{6}{|l|}{ Your age (years old) } \\
\hline $0-25$ & 135 & 17.8 & 16 & 25.0 & 0.167 \\
\hline $26-43$ years old & 405 & 53.4 & 25 & 39.1 & $x=5.060$ \\
\hline $44-59$ years old & 203 & 26.7 & 21 & 32.8 & \\
\hline $60-75$ years old & 16 & 2.1 & 2 & 3.1 & \\
\hline \multicolumn{6}{|c|}{ Region of your residence } \\
\hline North Kazakhstan & 86 & 11.3 & 9 & 14.1 & 0.005 \\
\hline South Kazakhstan & 197 & 26.0 & 3 & 4.7 & $x=16.530$ \\
\hline West Kazakhstan & 80 & 10.5 & 7 & 10.9 & \\
\hline East Kazakhstan & 135 & 17.8 & 17 & 26.6 & \\
\hline Central Kazakhstan & 70 & 9.2 & 10 & 15.6 & \\
\hline Nur-Sultan & 191 & 25.2 & 18 & 28.1 & \\
\hline \multicolumn{6}{|c|}{$\begin{array}{l}\text { Do you have time to use methods for the early diagnosis of cognitive impairment in the } \\
\text { elderly during admission? }\end{array}$} \\
\hline Yes & 454 & 59.8 & 15 & 23.4 & $p<0.001(0.000)$ \\
\hline No & 305 & 40.2 & 49 & 76.6 & $X=31.866$ \\
\hline \multicolumn{6}{|l|}{ Education } \\
\hline Higher & 391 & 51.5 & 21 & 32.8 & 0.004 \\
\hline Secondary & 368 & 48.5 & 43 & 67.2 & $X=8.258$ \\
\hline \multicolumn{6}{|l|}{ Work experience } \\
\hline $0-0.99$ & 75 & 9.9 & 8 & 12.5 & 0.428 \\
\hline $1-10$ & 378 & 49.9 & 25 & 39.1 & $X=2.774$ \\
\hline $11-20$ & 127 & 16.8 & 13 & 20.3 & \\
\hline $21-\ldots$. & 178 & 23.5 & 18 & 28.1 & \\
\hline
\end{tabular}

\section{Discussion}

After the WHO International Conference on PHC in Alma-Ata on September 12, 1978, the development of primary health care $\mathrm{PHC}$ ) became one of the most important ways of developing the health systems of all countries and PHC was defined as the "first contact zone" (or level of community service) of the population with health services and as the first stage of protecting public health. Today it is already universally recognized that a strong $\mathrm{PHC}$ system provides better indicators of public health at a lower cost and higher public satisfaction with medical care. Many of the health problems can be solved by creating a sustainable PHC system. Therefore, the process of improving and strengthening this service continues throughout the world, the main direction of which is focusing on the needs of the population as a whole and each family individually [19].

The Minister of Health of the Republic of Kazakhstan signed an order "On approval of the main directions of development of $\mathrm{PHC}$ in the Republic of Kazakhstan for 2018-2022" and an action plan for 20182019 on the implementation of the main directions of development of PHC. PHC in Kazakhstan includes premedical or qualified medical care without round-theclock medical supervision. It is first of all:

- Outpatient reception and home care of the attached population with the diagnosis and treatment of the most common diseases, as well as injuries, poisoning and other emergency conditions

- Protection of the family, motherhood, fatherhood, and childhood, including family planning

- $\quad$ Provision of drugs within the framework of the guaranteed volume of medical care

Preventive measures and identification of risk factors

Screening studies for the early detection of diseases, etc. [20].

A doctor is admitted on the day of treatment, the standard of service time for 1 patient is $15 \mathrm{~min}$. The waiting time for a consultation of a specialist is on average $7-10$ days [21].

In many European countries, Health Centers have been created with a doctor and his assistant (paramedical staff), who are obliged to deal with identification, diagnosis, treatment, sanitaryeducational work, anti-epidemic measures, and the collection of statistical material. Accordingly, in Europe, GP training programs provide for a minimum of 3-6 years after basic medical education (6 years or $5500 \mathrm{~h}$ ) and 3 years of special training (Directive 2005/36/EC) with an emphasis on practical training. In the Republic of Kazakhstan, GP and district therapists are trained in the specialty "General Medicine" (GOSO RK 3.08.4752006) with a training period of $5+2$, which includes basic training for 5 years and 2 years in an internship in the specialties of "General practitioner" "And" Therapy. After graduation, graduates are given the right to the independent practice of clinical practice in general medical practice and district therapy [22].

The problem of $\mathrm{Cl}$ currently occupies a leading position for many reasons. The first is a progressive increase in the number of such patients in whom the 
resulting disorders lead to a decrease in the quality of life, disruption of social and professional activity, and in some cases to disability and the development of complete dependence on others, in case of dementia. The second is the low coverage by specialist doctors (neurologists, psychiatrists, neuropsychologists, etc.) at those stages of the development of the disease when you can really do something and prevent the further progression of the condition. Third, the lack of real knowledge and practical skills in the early diagnosis of $\mathrm{Cl}$ in primary care physicians, in those who see the patient first and observe for a sufficiently long time until severe symptoms of dementia appear. Another reason is possible - the lack of understanding by the therapist or cardiologist of the importance of such an intervention. Of course, the interconnection of all causes makes this problem quite complicated [23], [24].

A similar study was conducted in Russia by Gantman. A survey of 65 doctors working in outpatient public and private institutions. Most (47 people, $72 \%$ ) of doctors of various therapeutic specialties answered that they knew how to detect dementia. Several conclusions were drawn from the survey of doctors: (1) Not all doctors know the techniques for detecting dementia. This is due to the fact that the program of Russian medical universities does not include modern recommendations in this area; (2) knowledge of how to detect dementia is not enough to put it into everyday practice. Doctors need motivation (understanding how important this diagnostic procedure) and communication skills to communicate with patients and their relatives on topics related to cognitive functions [25]. Researchers in Switzerland found that more than half of the surveyed GPs (57\%) said that caring relatives often requested a diagnostic assessment after noticing $\mathrm{Cl}$ or changes in patient's behavior. About half of the respondents reported that $\mathrm{Cl}$ or behavioral changes were often seen by patients $(49 \%)$ or by the GPs $(45 \%)$. Eight percent of GPs initiated a diagnostic evaluation in the context of a screening test, which means they "proactively" asked older patients at risk of developing dementia about their memory and suggested a screening test [18]. A study in England showed that older doctors were more confident in diagnosing and advising about dementia, but less often felt that early diagnosis was helpful, on the contrary, young doctors were more positive and felt that much could be done for improving. GPs believed that they did not have sufficient basic and subsequent qualifications for dementia, and general knowledge of dementia was low [17]. In a cross-sectional survey, 292 German therapists answered on 37 questions regarding to actual knowledge of dementia. Linear regression analysis revealed a significant relationship between the assessment of the knowledge test and the age of GPs and their relationship to dementia [16]. A study by Irish scientists based on surveys of GPs $(n=300)$ found that doctors more often blamed themselves than the health-care system, their patients or family members for the late detection of dementia in primary care. Stigma was the main obstacle to prevent GPs from being more active in this area. Village doctors felt that access to diagnostic services was geographically disadvantaged. The results provided strong evidence that training and access to diagnostic services were just two of several different structural and ideological barriers that GPs face when trying to diagnose dementia. Future educational support should be developed for GPs that will focus on these areas [26].

Hence, the results of our study indicate that a little more than half of the medical workers who participated in the study check older people for early $\mathrm{Cl}$ and have enough time for this while taking. At the same time, a large number of respondents want to learn methods for the early diagnosis of $\mathrm{Cl}$. The presence of time during admission, the region of residence and the desire to study affect whether elder people check for early $\mathrm{Cl}$ or not, in turn, specialty, education, gender, nationality, age, and work experience do not affect. We have identified a relationship of age, region of residence with the availability of time during admission to use methods for early diagnosis of $\mathrm{Cl}$, while it was absent with work experience. The region of residence, the availability of time during admission, and education influenced on respondents' desire to learn early diagnosis methods, while age and work experience did not.

This cross-sectional study has some limitations that have to be taken into consideration when interpreting the results. Respondents may not always be honest in their answers, it may distort the results. Selective sampling is also a constraint. Results become outdated over time. However, it is the first study where took participation many medical workers from all region of Kazakhstan. We used the international experience for detection knowledge of medical workers of Kazakhstan about early diagnosis of cognitive disorders in elder people.

\section{Conclusion}

Our study shows that the problem of early diagnosis of $\mathrm{Cl}$ in the elderly at the $\mathrm{PHC}$ level is relevant and not fully understood. Since the primary care doctor is the first to suspect $\mathrm{Cl}$, it is very important that they have sufficient knowledge in this area. GPs at the time of admission need to use simple and time-consuming methods of early diagnosis since the time of admission is limited to one person. Early diagnosis of $\mathrm{Cl}$ at the $\mathrm{PHC}$ level is a key element in the fight against such a serious condition as dementia. 


\section{Acknowledgment}

The authors would like to thank the administration of Semey Medical University.

\section{References}

1. Damulina Al, Kadykov AS. Cognitive impairment in chronic cerebral ischemia. Farmateka. 2014;10:63-9.

2. Novikova IA, Soloviev AG, Popov VV. Cognitive and affective disorders in the elderly. Adv Gerontol. 2017;30(3):442-449. PMid:28849892

3. Kiral K, Ozge A, Sungur MA, Tasdelen B. Detection of memory impairment in a community-based system: A collaborative study. Health Soc Work. 2013;38(2):89-96. https://doi.org/10.1093/ hsw/hlt004

\section{PMid:23865286}

4. Bianchetti A, Ferrara N, Padovani A, Scarpini E, Trabucchi M Maggi S. Timely detection of mild cognitive impairment in Italy: An expert opinion. J Alzheimers Dis. 2019;68(4):1401-14. https://doi.org/10.3233/jad-181253 PMid:30958367

5. Solomon PR, Murphy CA. Should we screen for Alzheimer's disease? A review of the evidence for and against screening Alzheimer's disease in primary care practice. Geriatrics. 2005;60(11):26-31 PMid:16287338

6. Prince $M$, Comas-Herrera A, Knapp M, Guerchet $M$, Karagiannidou M. World Alzheimer Report 2016-improving Health Care for People with Dementia-coverage, Quality and Costs Now and in the Future. London: Alzheimer's Disease International; 2016.

7. Dixon J, Ferdinand M, D'Amico F, Knapp M. Exploring the cost effectiveness of a one-off screen for dementia (for people aged 75 years in England and Wales). Int J Geriatr Psychiatry. 2015;30(5):446-52. https://doi.org/10.1002/gps.4158 PMid:25043227

8. Trukhan DI, Mazurov AL. Mild to moderate cognitive impairment: Current issues of diagnosis and treatment in primary health care. Consilium Med. 2016;18(2):74-80. https:// doi.org/10.26442/2075-1753_2016.2.74-80

9. Lorentz WJ, Scanlan JM, Borson S. Brief screening tests for dementia. Can J Psych. 2002;47(8):723-33. https://doi. org/10.1177/070674370204700803

PMid: 12420650

10. Zakharov VV. Neuropsychological tests. Necessity and applicability. Consilium Med. 2011;13(2):98-106.

11. Kostev K, Osina GG. Treatment patterns of patients with allcause dementia in Russia. J Alzheimers Dis Rep. 2020;4(1):914. https://doi.org/10.3233/adr-190144 PMid:32104783

12. Thomas DW, Yeshmanova A, Akanova A, Umutbayeva G, Abikulova A, Chaikovska V. Development of a memory center for older adults in Almaty, Kazakhstan: Innovative practice. Dementia (London). 2017;16(5):665-72. https://doi. org/10.1177/1471301216636491

\section{PMid:26951363}

13. Kuanova LB. New diagnostic criteria for Alzheimer's disease and mild cognitive impairment. Kazakhstans Health J. 2015;9(40):31-7.

14. Soleimani R, Shokrgozar S, Fallahi M, Kafi H, Kiani M. An investigation into the prevalence of cognitive impairment and the performance of older adults in Guilan province. J Med Life. 2018;11(3):247-53. https://doi.org/10.25122/jml-2018-0017 PMid:30364719

15. ALCOVE Project. The European Joint Action on Dementia. Synthesis Report 2013. Alzheimer Cooperative Valuation in Europe (ALCOVE); 2013. Available from: http://www. alcoveproject.eu/images/pdf/ALCOVE REPORTVF.pdf. [Last accessed on 2016 Nov 17]. SYNTHESIS

16. Pentzek M, Abholz HH, Ostapczuk M, Altiner A, Wollny A, Fuchs A. Dementia knowledge among general practitioners: First results and psychometric properties of a new instrument. Int Psychogeriatr. 2009;21(6):1105-15. https://doi.org/10.1017/ s1041610209990500 PMid:19602307

17. Ahmad S, Orrell M, Iliffe S, Gracie A. GPs' attitudes, awareness, and practice regarding early diagnosis of dementia. $\mathrm{Br} \mathrm{J}$ Gen Pract. 2010;60(578):e360-5. https://doi.org/10.3399/ bjgp10x515386

PMid:20849686

18. Stéphanie G, Andreas MU, Reto KW, Mueller $\mathrm{Y}$, Streit $\mathrm{S}$, Essig $\mathrm{S}$, et al. Early diagnosis and management of dementia in general practice-how do Swiss GPs meet the challenge? Swiss Med Wkly. 2018;148:w14695. https://doi.org/10.4414/ smw.2018.14695

PMid:30576570

19. Smirnova EN, Radaeva AB, Malkovets MV, Mezhueva TI, Plahotya LP. Organization of Primary Health Care to the Population. Minsk: World Health Organization; 2007. p. 65.

20. World Health Organization. The Order of the Minister of Health of the Republic of Kazakhstan No. 461, On Approval of the Main Directions for the Development of Primary Health Care in the Republic of Kazakhstan for 2018-2022. Geneva: World Health Organization; 2018.

21. World Health Organization. Order of the Minister of Health and Social Development of the Republic of Kazakhstan No. 85, On Approval of the Standard for the Organization of Primary Health care in the Republic of Kazakhstan. Geneva: World Health Organization; 2016.

22. Aydarkhanova KK, Otynshiev BN, Esengeldinova ZN Mustafayeva NS. Competence-based approach to training general practitioners in Kazakhstan. Herald ASIAME. 2012;2:32-5.

23. Shishkova VN. Cognitive impairment as a universal clinical syndrome in the practice of a therapist. Ther Arch. 2014;86(11):128-34.

24. Kim IV, Bochkareva EV, Varakin YY, Kokurina EV. Application of a screening technique to detect chronic forms of cerebrovascular diseases in primary health care facilities. Prevent Med. 2013;16(4):27-30.

25. Gantman MV. Detection of dementia on an outpatient basis for the elderly. Modern Ther Psychiatry Neurol. 2016; No3.

26. Cahill S, Clark M, O'Connell H, Lawlor B, Coen RF, Walsh C. The attitudes and practices of general practitioners regarding dementia diagnosis in Ireland. Int J Geriatr Psychiatry. 2008;23(7):663-9. https://doi.org/10.1002/gps.1956 PMid:18229882 